\title{
DATING SIMULATOR IN INDONESIA
}

\author{
Dominikus Reynard Darmawan \\ Game Technology UNIKA \\ Jl. Pawiyatan Luhur, Semarang, Indonesia \\ Dominikusreynard@gmail.com
}

\begin{abstract}
Japanese culture has been entering Indonesia, especially anime, fashion, and dating sim. How big the effect of the existence of dating sim in Indonesia?
\end{abstract}

Keywords - Dating Sim, Dating Simulator,
Simulator, Japanese game

\section{INTRODUCTION}

After Japanese animation (anime) entering Indonesia, Japanese culture is like dominate Indonesian culture. Almost all of people know what anime is and they start to learn Japanese culture from anime. They also start applying it in their daily activities. After the writer saw that phenomenon, the writer will identify the game that is very popular in Japan and in anime lover communities. This game is "Dating Simulator". The genre of this game starts to grow in group of otaku in Japan. In this game, a player can date with the character he wants to date. Now, many games of dating sim become an idea of anime. Thus, for people who do not know about dating sim they will know about it after watching anime. From all dating sim games, "Love Plus" is the most popular dating sim game. Because many people in Indonesia who force themselves to follow culture, fashion, and everything from Japan, the writer wants to know if the genre of the game like dating sim has entered Indonesia or not. If it has already entered Indonesia, how much its growth in Indonesia, how that game competes with other games in International market, and if there is any positive or negative effect to the player.

\section{LITERATURE REVIEW}

Dating Simulator is a game which simulates dating life. This game starts to become the favorite one since the player can date the character he/she likes easily and start his/her daily life with his virtual girlfriend/boyfriend.

\subsection{Gameplay}

Gameplay in dating simulator game made in Japan is almost same as visual novel. The difference is the player can move freely, and he has some status like "Smart", "Power", "Money", etc. Those are needed to get a girl. There will be more than one girl, so the player can choose which one he wants to date. After the player finishes the story, the player can start to date with the character he chooses. He can do anything with that character like talk to her, send her a message, go to vacation together, etc. Because this game is actually for portable console like PSP, 3DS and other kinds of portable console. Therefore, this game has real time that make it looks like real.

The player can date his girlfriend just like in time same as in his real life. For portable console which using touchscreen, the player can touch his virtual girlfriend. Moreover, that makes this game special is the player must choose the right answer to make the story. That is why a little mistake can make a different ending. That makes many people like to repeat playing the game just to see all secret ending.

\subsection{Dating Simulator as sub-genre}

Mostly, a game includes dating sim as a sub-genre. It means it is not a main genre like GTA, Persona, etc. However, now 
many people start to use dating simulator as a main-genre like Love Plus, Sunrider Academy, etc.

\subsection{Advantages of Dating Simulator}

If people talk about advantages of dating simulator, this game is very entertaining for someone who does not have any girlfriend. Not only that advantage, dating sim also has a story- not just dating with the character, the player will be invited to know the fictional character in game. Besides story and dating, this game provides gameplay that is more challenging where the player must understand how to manage the time. BY managing the time, the player can complete the thing that he needs to win every character's heart in this game. Another advantage is many anime become dating sim, so for every otaku which wants to enter their favorite anime, the player will play the dating sim from their favorite anime. The last but not least, the unique of this game is the ending which is more than one, so it can make the player feels curious. It also makes the player wants to repeat playing the game again and again just to see different ending.

\subsection{Disadvantages of Dating Simulator}

Not only has advantages, dating sim also has disadvantages. For example, for people who do not like to read story, they will get bored very soon. Then, they will stop playing and not finish the game. Dating simulator also can make people focused on game and leave their daily lives because the system in this game is like tamagochi, so people must take care of it every time. They must often look in it. That is why if people play it in PC they will get trouble. Since people must often look in their pc and they cannot bring their pc everywhere, that is why Japan makes dating simulator game for portable console.

\subsection{Dating Simulator in Indonesia}

From survey that the writer did in September 2015, the writer found the comparison between people in Indonesia who know about dating sim and those who do not know is $5: 12$. The writer thinks that dating sim has already entered in Indonesia, but people in Indonesia mostly know about dating sim not from the game made by Japan, but from the game called The Sims. Meanwhile, the game from Japan that people mostly know is Love Plus.

\section{6 is Dating Simulator just for males?}

Maybe this game sounds like for a lonely man who does not have a girlfriend, but many people do not know that many dating sim games are created for females, even there is a game for men that is remade for women. Thus, this game is not limited to gender.

\section{RESEARCH METHODOLOGY}

Method with 21 questions and 34 respondents. Opened from 21 August - 3 October 2014

The survey shows that the comparison between people in Indonesia who know about dating sim and those who do not know is 5:12. It also shows that dating sim almost half of Indonesian people play this kind of game.

$50 \%$ of people know dating sim from internet, 30\% from anime and 20\% from their friends. Many people access internet than people who know anime, and people who play dating sim feel a little embarrassed to talk about it to their friends.

The survey shows that $60 \%$ of people think that dating sim and visual novel are different. Meanwhile, $40 \%$ of people think they are the same because many people think that dating sim is a simulator for dating, while visual novel is just a novel which is visualized. However, there are people who think that dating sim and visual 
novel are the same game because the gameplay between dating sim and visual novel is almost the same, but actually there is a different in the game system.

The survey shows that $40 \%$ of people like dating sim, $40 \%$ like visual novel and $20 \%$ like both. This shows that dating sim and visual novel are balanced because some people like simple games like visual novel and some people like complicated games like dating sim.

$60 \%$ of people in Indonesia start to know dating sim between 16-20 years old, 30\% start to know between 11-15 years old, and the rest is between $0-10$ years old. This thing can be caused for many people in 11-20 years old are interested in dating, and maybe they start to like virtual characters and they want to date them, so they look for the way, and finally they find this dating sim.

$40 \%$ of people play dating sim less than one day, $30 \%$ of people play less than one week, $20 \%$ play it less than one years, and the rest is less than one month. This shows that Indonesian people are very easy to get bored so they play it less than one day. It happens maybe because they just finish the story once and they get bored.

After they are asked what they like from dating sim, $50 \%$ like the graphic and $50 \%$ people like the story. This shows that both graphic and story are very important in dating sim. A half of them like to see a very beautiful character and do not care about the story, and the rest wants to see a good story without caring the graphic as long as they understand the story.

For those who like the graphic, $80 \%$ of them like 3D, but 20\% like 2D. Evidently, almost all Indonesian people like realistic graphic which looks like real.

The survey shows that $60 \%$ of Indonesian people mostly still using PC for gaming. However, dating sim which is created from Japan is mostly made for portable console, this is one of obstacle for dating sim to enter Indonesia. This is because Indonesian people think that with only one PC they can play all kind of game from every console with emulator, even though the sensation when playing the game in PC and console is different.

The results of the survey about the social life from the player after playing dating simulator are $55.6 \%$ of people get some new friends, and $44.6 \%$ do not get any change. This thing proves that dating simulator gives a positive effect to Indonesian people who play it. This game also can increase someone's social life, so they can get some new friends, and it does not make someone lost their friends. This is because by playing this game and meeting with new friends in this game, people can get a new topic in conversation, or maybe if they see someone play the same kind of game they can start to talk about it. Why the writer can talk like that? Because in this game people can talk anything with their partners, like the secret, the detail, or the secret ending.

When people who play this game ask if this game is good or bad for them, $88.8 \%$ say that it is good for themselves. The reason is because this game is not like other games which have violent or bad influence in it. In this game, there is only love and education. This game also teaches people to talk to someone they like or to get someone they like. Some people say that this game makes them not lonely anymore.

\section{RESULTS AND DISCUSSION}

Many Indonesian people has known about dating sim from The Sims and Love Plus game. They get information about it mostly from internet than anime. However, the comparison between people who think that dating sim and visual novel are the same game and for those who think that dating sim and visual novel are different is 2:3. The competition between dating sim and visual novel is the same. In Indonesia most people know dating sim from internet, anime and from their friend. Even though in Indonesia there are many people who love anime, but not all of them know about dating sim. 
From the graphic and the story, the competition is balance because some people want to have a nice graphic, and some want to see a good story. While for graphic itself people in Indonesia prefer to see 3D graphic than 2D. Because this game is for dating, so they want to see their girlfriend or boyfriend as good as possible. For the graphic type, Indonesian people prefer to see it in 3D than 2D. Because this game is about dating, that is why the players are mostly from 16-20 years old. That is a time where they want to have a girlfriend/boyfriend. From the motivation of Indonesian people, we can see that people are very curious about something new and always want to try something new. Most people in Indonesia still use PC than other mobile consoles to play the game. Moreover, this game does not make people become anti-social, but it makes people become friendlier. They can get new friends to discuss anything about this game. In Indonesian, many people still do not care with what other people play, so people who play dating simulator do not get any insult from someone who watches them playing dating sim. Therefore, by playing this game, people do not get any positive respond or negative respond from other people. For other people, they think that it is normal to play dating sim and for dating sim player, they think that dating sim is good for them. They think there is no negative effect from it because there is no violent, porn or any other bad things in this game. The player just need to do dating with the character they like. Through this game, people can learn how to approach with someone, talk to someone about falling in love, etc.

\section{CONCLUSIONS}

As the result, the possibility of dating sim will success in Indonesia is $70 \%$ because in Indonesia there are not many people know and are interested in dating sim. However, because the game from Indonesia is not too much, the possibility that people will be curious to try a new thing can become good chance to develop this genre of game in
Indonesia. Moreover, this game does not have any bad effect in social life, it will help people who play it to get new friends. Because the amount of people who play visual novel and dating sim are almost the same, it will be better to develop the game which can unite the dating sim and the visual novel.

\section{REFERENCES}

[1] http://bwin-bwin.blogspot.co.id/2011/06/datingsim-game.html. Demina, June 18, 2011

[2] http://kotaku.com/love-plus-makes-you-careabout-a-virtual-girl-1570690624.Richard Eisenbeis May 5, 2014

[3] Taylor, Emily, Dating-Simulation Games: Leisure and Gaming of Japanese Youth Culture. Southeast Review of Asian Studies. Volume 29, (2007):p.192-208. 